\title{
Cross-Country Economic Espionage and Investment in Research and Development
}

\author{
Po-Lu Chen ${ }^{1}$ \\ ${ }^{1}$ Department of Economics, Tamkang University, New Taipei City, Taiwan \\ Correspondence: Po-Lu Chen, Department of Economics, Tamkang University, No.151, Yingzhuan Rd., Tamsui \\ Dist., New Taipei City 25137, Taiwan. Tel: 886-2-2621-5656 ext. 2975. E-mail: poluchen@ gmail.com
}

Received: January 20, 2016

Accepted: February 27, 2016

Online Published: March 25, 2016

doi:10.5539/ijef.v8n4p146

URL: http://dx.doi.org/10.5539/ijef.v8n4p146

\begin{abstract}
This paper investigates the impact of cross-country economic espionage on innovation incentives and welfare by considering both ex ante and ex post effects of espionage. I consider two firms residing in two countries with two types of innovation, cost-reducing research and development (R\&D) and information technology $R \& D$, and find that espionage activity reduces both firms' investment in cost-reducing R\&D. The change in consumer's welfare due to espionage depends on two offsetting effects and is ambiguous. I also discuss the effect of sales ban policy on deterring espionage. I find that sales ban policy may alternatively encourage investment in espionage activities if market size is small. Whether sales ban policy can improve consumer's welfare depends on the market size. When market size is large that espionage activities are deterred by sales ban, then more capital devoted to cost-reducing R\&D leads to higher consumer welfare. However, if market size is small that espionage is not deterred, then monopolistic position of the local firm under sales ban policy hurts local consumers.
\end{abstract}

Keywords: espionage, research and development, R\&D, sales ban, information technology, internet hacking

\section{Introduction}

Economic espionage is an important and long-lasting issue in human history. American firms are estimated to bear annual extra cost due to economic espionage up to 8.16 billion dollars. Firms in other countries also face similar problems. For example, resigned employees from the Taiwanese audio chip designer C-Media Electronics disclosed commercial secrets to a Chinese rival. Another example is that a senior manager of HTC, a Taiwanese smartphone manufacturer, was accused of being the spy of a Chinese competitor in 2013. Similar stories can also be seen in French car manufacturer Renault.

Espionage comes in different forms and the development in Internet makes espionage even more active in recent years. As reported by TIMES in May 2014, "Attorney General Eric Holder unveiled economic espionage charges against Chinese military officials for targeting American companies." In 2013, The New York Times also reported that it had been hacked from China. Aforementioned cases reveal that economic espionage is crucial in national security as well as economic development and thus the impact of economic espionage is worthy of study.

Economic literature regarding espionage can be categorized in two strands: non-noisy signal model and noisy signal model. The first strand assumes that information successfully gathered through espionage activities is always correct. If espionage activities fail, then no information is obtained. Papers in the first strand include Matsui (1989), Whitney and Gaisford (1996, 1999), and Billand et al. (2010). Matsui (1989) considers a two-player repeated game. Each player has a probability to detect rival's action. Given the probability, this paper finds that if the probability of successful detection is low, then any subgame perfect Nash equilibrium in this game is Pareto efficient. Whitney and Gaisford $(1996,1999)$ consider a duopoly Cournot model where there are two firms residing in two different countries. Each firm can reduce production cost if it successfully steals rival's technology through espionage. They find that business spy is an efficient way to achieve technology transfer and thus it is beneficial to consumers as well as the firm engaging in espionage activities. In addition, since sending spy can reduce home firm's cost, national-supported espionage is parallel to subsidy in strategic trade policy. Billand et al. (2010) consider spying in multi-market oligopolies. They assume oligopolistic firms produce heterogeneous products and compete in quantity. Suppose a firm can choose whether or not to develop a 
connection with a rival to gather information through espionage. If the connection is developed, the firm sending out the spy can increase the quality of its product. They find that even if espionage is costless, firms may or may not engage in espionage activities. They also argue that although espionage is helpful for quality improving, it can be harmful for consumers and social welfare.

The second strand of literature regarding espionage considers noisy signal received through espionage activities. Solan and Yariv (2004) use a 2×2 normal form game to discuss how espionage affects players' decision. They assume the signal received through espionage may be incorrect, but a player can pay higher wage to hire a more capable spy to obtain better signal. They find that the cost of spy only affects players on whether or not to hire a spy, but not the quality of the spy. They also find that players will believe in the signal they receive from the spy even though they realize that the signal may be incorrect. Provan (2008) uses linear programming solutions to consider the use of decoy strategies to mislead spies. Ho (2008) discusses double crossing issue in espionage. She finds that the spy is over rewarded because the client of the spy needs to pay more to avoid double crossing. Nevertheless, the over reward problem can be mitigated by hiring more spies to develop a competitive mechanism. Barrachina et al. (2014) consider espionage and entry deterrence. They assume a potential entrant owns an Intelligence System to collect information regarding incumbent's action. They show that if the precision of the Intelligence System is commonly known by the incumbent and the potential entrant, then entrant's espionage activity actually hurts itself because the incumbent can signal-jam to affect the entrant's decision. The incumbent benefits more when Intelligence System is more precise.

The current paper follows the assumption in the first strand, in which signal received through espionage is correct but it is possible to fail in espionage activities. The purpose of this study is to discuss the impact of cross-country espionage activities on innovation investment. This paper has a closer structure to Whitney and Gaisford (1996, 1999), in which two firms residing in two countries produce homogeneous products and compete in quantity (Note 1). Unlike Whitney and Gaisford $(1996,1999)$ who assume firms' technology is given, I consider an investment stage in prior to the Cournot competition. Both firms engage in two kinds of innovation: cost-reducing innovation and information technology (IT) innovation. The outcomes of both innovations are uncertain. If the cost-reducing innovation by a particular firm succeeds, then its unit production cost will fall. The IT innovation goes as follows. The high-cost firm can develop information system to hack into the low-cost firm and steal the technology for production, while the high-cost firm can invest to enhance information security to prevent technology leakage. By considering investment incentives, I find that espionage reduces both firms' investment in cost-reducing innovation, but the welfare impact on consumers is uncertain. The reason is as follows. High-cost firm reduces cost-reducing investment because espionage is an alternative to obtain sophisticated technology, while the reduction in low-cost firm's cost-reducing investment is due to free-rider problem. For welfare consequence on consumers, espionage has two effects. The first effect is so-called technology transfer effect, which is addressed in Whitney and Gaisford $(1996,1999)$. This effect is positive to consumer surplus. The second effect comes from the reduction in cost-reducing investment, and is negative to consumer welfare. Whether consumers are hurt by espionage or not depends on which effect dominates.

I also discuss the welfare consequence of IT subsidy and sales ban policy. IT subsidy on the firm whose unit cost is high (low) is beneficial (detrimental) to consumer surplus. The reason is that IT subsidy on low-cost (high) firm impedes (encourages) technology transfer, which reduces (enhances) the positive effect of espionage on consumer's welfare. The analysis of sales ban policy indicates that to deter espionage by sales ban, the market size needs to be sufficiently large. Otherwise, sales ban may instead increase investment in espionage activity. I also find that consumers are worse off with sales ban if sales ban can not deter espionage. However, when market size is large such that espionage is deterred by sales ban, then consumers are better off with sales ban.

This paper is organized as follows. Section 2 provides the model to address firms' investment and pricing behavior. Section 3 analyzes consumer's welfare change due to espionage and trade policies. Section 4 concludes.

\section{Method}

Two firms (A and B) produce homogeneous products and compete in quantity in two different countries at time $\mathrm{t}$ $=\mathrm{t}_{1}$. Two countries have identical and linear market demand function, denoted by $P=R-Q$, where $P$ and $Q$ represent price and quantity respectively and $R$ measures market size. The marginal cost of firm A and firm B are $c_{M}$ and $c_{H}$ respectively, where $0<c_{M}<c_{H}$ to capture that firm A has sophisticated technology. Prior to the stage of production, at time $\mathrm{t}=\mathrm{t}_{0}$, each firm can engage in cost-reducing $\mathrm{R} \& \mathrm{D}$. For firm $i(i=\mathrm{A}, \mathrm{B})$, the probability to succeed in cost-reducing $\mathrm{R} \& \mathrm{D}$ is $\alpha_{i}\left(k_{\alpha}^{i}\right)$, where $k_{\alpha}^{i}$ is the capital devoted to cost-reducing $\mathrm{R} \& \mathrm{D}$ by firm $i$. For simplicity, it is assumed that the marginal cost has three levels: $c_{L}, c_{M}$, and $c_{H}$, where 
$0 \leq c_{L}<c_{M}<c_{H}$. Once firm $i$ 's cost-reducing R\&D succeeds, its marginal cost will decrease by one level. In addition, I assume $\alpha_{i}(0)=0$ and $\alpha_{i}^{\prime}\left(k_{\alpha}^{i}\right)>0>\alpha_{i}^{\prime \prime}\left(k_{\alpha}^{i}\right)$.

\subsection{No Economic Espionage}

In this benchmark case, suppose that two firms do not engage in espionage activities. For both firms, investing in cost-reducing $R \& D$ is the only way to reduce marginal cost. There are four possible outcomes of cost-reducing R\&D by two firms: $\{$ both firms succeed, A succeeds \& B fails, A fails \& B succeeds, both firms fail $\}$. Let the probability of aforementioned four outcomes be $\left\{\delta_{L M}, \delta_{L H}, \delta_{M M}, \delta_{M H}\right\}$, where $\delta_{x y}$ denotes the probability of facing the case in which firm A has marginal cost $c_{x} \quad(x=L, M)$ and firm B has marginal cost $c_{y} \quad(y=M, H)$. It is straightforward to calculate $\delta_{L M}=\alpha_{A} \alpha_{B}, \quad \delta_{L H}=\alpha_{A}\left(1-\alpha_{B}\right), \delta_{M M}=\left(1-\alpha_{A}\right) \alpha_{B}$, and $\delta_{M H}=\left(1-\alpha_{A}\right)\left(1-\alpha_{B}\right)$. By backward induction, substituting the optimal output obtained in the second stage to the expected profit function, firm $i$ faces the following profit maximization problem (Note 2):

$$
\max _{\left\{k_{\alpha}^{i}\right\}} \prod_{i}=2\left[\delta_{M H} \pi_{i}\left(c_{M}, c_{H}\right)+\delta_{L H} \pi_{i}\left(c_{L}, c_{H}\right)+\delta_{L M} \pi_{i}\left(c_{L}, c_{M}\right)+\delta_{M M} \pi_{i}\left(c_{M}, c_{M}\right)\right]-k_{\alpha}^{i}
$$

where $\pi_{A}\left(c_{x}, \mathbf{c}_{y}\right)=\left(\left(R-2 c_{x}+c_{y}\right) / 3\right)^{2}, \quad \pi_{B}\left(c_{x}, c_{y}\right)=\left(\left(R+c_{x}-2 c_{y}\right) / 3\right)^{2}$. The optimal capital devoted to cost-reducing

$\mathrm{R} \& \mathrm{D},\left(k_{\alpha}^{A^{*}}, k_{\alpha}^{B^{*}}\right)$, satisfies:

$$
\begin{aligned}
& \alpha_{A}{ }^{\prime}\left(k_{\alpha}^{A^{*}}\right)=1 /(2 \Phi) \\
& \alpha_{B}{ }^{\prime}\left(k_{\alpha}^{B^{*}}\right)=1 /(2 \Psi)
\end{aligned}
$$

where $\Phi=\left(\left(1-\alpha_{B}\right)\left[\pi_{A}\left(c_{L}, c_{H}\right)-\pi_{A}\left(c_{M}, c_{H}\right)\right]+\alpha_{B}\left[\pi_{A}\left(c_{L}, c_{M}\right)-\pi_{A}\left(c_{M}, c_{M}\right)\right]\right)$ and $\Psi=\left(\left(1-\alpha_{A}\right)\left[\pi_{B}\left(c_{M}, c_{M}\right)-\pi_{B}\left(c_{M}, c_{H}\right)\right]+\alpha_{A}\left[\pi_{B}\left(c_{L}, c_{M}\right)-\pi_{B}\left(c_{L}, c_{H}\right)\right]\right)$

\subsection{Economic Espionage}

With espionage activities, both firms can also engage in IT investment. Let $\beta_{i}\left(k_{\beta}^{i}\right)$ be the probability of success in IT innovation. $k_{\beta}^{i}$ denotes the capital devoted to IT innovation by firm $i$. Similarly, we assume $\beta_{i}^{\prime}\left(k_{\beta}^{i}\right)>0>\beta_{i}^{\prime \prime}\left(k_{\beta}^{i}\right)$. Given firm A's initial IT protection level, if firm B succeeds in IT innovation, firm B can fully access firm A's knowledge. However, if firm A successfully enhances IT level, espionage activity by firm B is blocked. In short, firm A's knowhow is stolen by firm B only if firm B's IT innovation succeeds and firm A's IT innovation fails. There are two firms with two kinds of innovation and each innovation has two outcomes. Therefore, we have $(2 \times 2)^{2}=16$ possible outcomes, which lead to five corresponding cost combinations: $\left(c_{L}, c_{M}\right),\left(c_{L}, c_{L}\right),\left(c_{L}, c_{H}\right),\left(c_{M}, c_{M}\right)$, and $\left(c_{M}, c_{H}\right)$. Table 1 summarizes all possible cost combinations.

Table 1. Cost structure in corresponding occasions

\begin{tabular}{llllll}
\hline & Firm B & both Succeed & $\begin{array}{l}\text { only cost-reducing R\&D } \\
\text { succeeds }\end{array}$ & $\begin{array}{l}\text { only IT innovation } \\
\text { succeeds }\end{array}$ & both fail \\
\hline Firm A & Probability & $\alpha_{B} \beta_{B}$ & $\alpha_{B}\left(1-\beta_{B}\right)$ & $\left(1-\alpha_{B}\right) \beta_{B}$ & $\left(1-\alpha_{B}\right)\left(1-\beta_{B}\right)$ \\
$\begin{array}{l}\text { both Succeed } \\
\text { only cost-reducing }\end{array}$ & $\alpha_{A} \beta_{A}$ & $\left(c_{L}, c_{M}\right)$ & $\left(c_{L}, c_{M}\right)$ & $\left(c_{L}, c_{H}\right)$ & $\left(c_{L}, c_{H}\right)$ \\
$\begin{array}{l}\text { R\&D succeeds } \\
\text { only IT innovation } \\
\text { succeeds }\end{array}$ & $\alpha_{A}\left(1-\beta_{A}\right)$ & $\left(c_{L}, c_{L}\right)$ & $\left(c_{L}, c_{M}\right)$ & $\left(c_{L}, c_{L}\right)$ & $\left(c_{L}, c_{H}\right)$ \\
both fail & $\left(1-\alpha_{A}\right) \beta_{A}$ & $\left(c_{M}, c_{M}\right)$ & $\left(c_{M}, c_{M}\right)$ & $\left(c_{M}, c_{H}\right)$ & $\left(c_{M}, c_{H}\right)$ \\
\hline
\end{tabular}

Let $\tilde{\delta}_{r s}$ be the probability of cost combination $\left(c_{r}, c_{s}\right)$ to occur, where $r=L, M$ and $s=L, M, H$. From Table 1 , we can calculate: 


$$
\begin{aligned}
\tilde{\delta}_{L M}= & \alpha_{A} \beta_{A} \alpha_{B} \beta_{B}+\alpha_{A} \beta_{A} \alpha_{B}\left(1-\beta_{B}\right)+\alpha_{A}\left(1-\beta_{A}\right) \alpha_{B}\left(1-\beta_{B}\right) \\
\tilde{\delta}_{L L}= & \alpha_{A}\left(1-\beta_{A}\right) \alpha_{B} \beta_{B}+\alpha_{A}\left(1-\beta_{A}\right)\left(1-\alpha_{B}\right) \beta_{B} \\
\tilde{\delta}_{L H}= & \alpha_{A} \beta_{A}\left(1-\alpha_{B}\right) \beta_{B}+\alpha_{A} \beta_{A}\left(1-\alpha_{B}\right)\left(1-\beta_{B}\right)+ \\
& \alpha_{A}\left(1-\beta_{A}\right)\left(1-\alpha_{B}\right)\left(1-\beta_{B}\right) \\
\tilde{\delta}_{M M}= & \left(1-\alpha_{A}\right) \beta_{A} \alpha_{B} \beta_{B}+\left(1-\alpha_{A}\right) \beta_{A} \alpha_{B}\left(1-\beta_{B}\right)+ \\
& \left(1-\alpha_{A}\right)\left(1-\beta_{A}\right) \alpha_{B} \beta_{B}+\left(1-\alpha_{A}\right)\left(1-\beta_{A}\right) \alpha_{B}\left(1-\beta_{B}\right)+ \\
& \left(1-\alpha_{A}\right)\left(1-\beta_{A}\right)\left(1-\alpha_{B}\right) \beta_{B} \\
\tilde{\delta}_{M H}= & \left(1-\alpha_{A}\right) \beta_{A}\left(1-\alpha_{B}\right) \beta_{B}+\left(1-\alpha_{A}\right) \beta_{A}\left(1-\alpha_{B}\right)\left(1-\beta_{B}\right)+ \\
& \left(1-\alpha_{A}\right)\left(1-\beta_{A}\right)\left(1-\alpha_{B}\right)\left(1-\beta_{B}\right)
\end{aligned}
$$

Firm $i(i=\mathrm{A}, \mathrm{B})$ maximizes expected profit:

$$
\max _{\left\{k_{k}^{i}, k_{\beta}^{i}\right\}} \tilde{\Pi}_{i}=2\left[\tilde{\delta}_{M H} \pi_{i}\left(c_{M}, c_{H}\right)+\tilde{\delta}_{L H} \pi_{i}\left(c_{L}, c_{H}\right)+\tilde{\delta}_{L M} \pi_{i}\left(c_{L}, c_{M}\right)+\tilde{\delta}_{M M} \pi_{i}\left(c_{M}, c_{M}\right)+\tilde{\delta}_{L L} \pi_{i}\left(c_{L}, c_{L}\right)\right]-k_{\alpha}^{i}-k_{\beta}^{i}
$$

Similarly, $\pi_{A}\left(c_{r}, \mathrm{c}_{s}\right)=\left(\left(R-2 c_{r}+c_{s}\right) / 3\right)^{2}, \quad \pi_{B}\left(c_{r}, c_{s}\right)=\left(\left(R+c_{r}-2 c_{s}\right) / 3\right)^{2}$. Equilibrium cost-reducing R\&D and IT investment by two firms $\left(\tilde{k}_{\alpha}^{A}, \tilde{k}_{\alpha}^{B}, \tilde{k}_{\beta}^{A}, \tilde{k}_{\beta}^{B}\right)$ satisfies the following first order conditions:

$$
\begin{aligned}
& \alpha_{A}{ }^{\prime}\left(\tilde{k}_{\alpha}^{A}\right)=1 / 2(\Phi+\Omega) \\
& \alpha_{B}^{\prime}\left(\tilde{k}_{\alpha}^{B}\right)=1 / 2\left(\left(1-\beta_{B}\left(1-\beta_{A}\right)\right) \Psi\right) \\
& \beta_{A}{ }^{\prime}\left(\tilde{k}_{\beta}^{A}\right)=1 /(2 \Theta) \\
& \beta_{B}{ }^{\prime}\left(\tilde{k}_{\beta}^{B}\right)=1 /(2 \Upsilon)
\end{aligned}
$$

where

$$
\begin{aligned}
& \Omega=\left(1-\alpha_{B}\right)\left(1-\beta_{A}\right) \beta_{B}\left[\Delta \pi_{A}\left(c_{M}\right)-\Delta \pi_{A}\left(c_{H}\right)\right]+\left(1-\beta_{A}\right) \beta_{B}\left[\pi_{A}\left(c_{L}, c_{L}\right)-\pi_{A}\left(c_{L}, c_{M}\right)\right] \Delta \pi_{A}\left(c_{M}\right)=\pi_{A}\left(c_{L}, c_{M}\right)-\pi_{A}\left(c_{M}, c_{M}\right), \\
& \Delta \pi_{A}\left(c_{H}\right)=\pi_{A}\left(c_{L}, c_{H}\right)-\pi_{A}\left(c_{M}, c_{H}\right), \\
& \Theta= \alpha_{A} \beta_{B}\left[\pi_{A}\left(c_{L}, c_{H}\right)-\pi_{A}\left(c_{L}, c_{L}\right)\right]-\alpha_{A} \alpha_{B} \beta_{B}\left[\pi_{A}\left(c_{L}, c_{H}\right)-\pi_{A}\left(c_{L}, c_{M}\right)\right]+\left(1-\alpha_{A}\right)\left(1-\alpha_{B}\right) \beta_{B}\left[\pi_{A}\left(c_{M}, c_{H}\right)-\pi_{A}\left(c_{M}, c_{M}\right)\right] \\
& \Upsilon=-\alpha_{A} \alpha_{B}\left(1-\beta_{A}\right)\left[\pi_{B}\left(c_{L}, c_{M}\right)-\pi_{B}\left(c_{L}, c_{H}\right)\right]+\alpha_{A}\left(1-\beta_{A}\right)\left[\pi_{B}\left(c_{L}, c_{L}\right)-\pi_{B}\left(c_{L}, c_{H}\right)\right]+ \\
&\left(1-\alpha_{A}\right)\left(1-\alpha_{B}\right)\left(1-\beta_{A}\right)\left[\pi_{B}\left(c_{M}, c_{M}\right)-\pi_{B}\left(c_{M}, c_{H}\right)\right]
\end{aligned}
$$

The impact of espionage activity on firm A's cost-reducing R\&D can be seen by comparing (6) to (2). Because $\Omega<0$ and $\alpha_{i}^{\prime}\left(k_{\alpha}^{i}\right)>0>\alpha_{i}^{\prime \prime}\left(k_{\alpha}^{i}\right)$, we find that $k_{\alpha}^{A^{*}}>\tilde{k}_{\alpha}^{A}$, which means that firm A's cost-reducing R\&D decreases if firm B engages in economic espionage (Note 3). Similarly, comparing (7) to (3), espionage activity also has a negative effect to firm B's investment in cost-reducing R\&D. The intuition behind this result is straightforward. The reason why espionage is harmful for firm A's investment incentive in cost-reducing R\&D is that firm A's expected gains from cost-reducing $R \& D$ are decreased by the threat of knowhow leakage. For firm $B$, if stealing the knowhow from the rival becomes a possible way to reduce unit production cost (i.e. $\beta_{B}>0$ and $\beta_{A}<1$ ), investment in IT innovation will be a substitute to investment in cost-reducing R\&D for firm B. Proposition 1 summarizes this result.

Proposition 1. Economic espionage has a negative effect on both firms' investment incentive in cost-reducing $R \& D$.

Investigating equations (6)-(9), we can identify the correlation between two kinds of investment and corresponding probability of success. The findings are summarized in Lemma 1.

Lemma 1. Ceteris paribus, the following relationship holds:

L.1) Firm A's cost-reducing $R \& D$ investment is positively correlated with $\beta_{A}$, but is negatively correlated with $\alpha_{B}$ and $\beta_{B}$.

L.2) Firm A's IT investment is positively correlated with $\alpha_{A}$ and $\beta_{B}$, but is negatively correlated with $\alpha_{B}$. 
L.3) Firm B's cost-reducing $R \& D$ investment is positively correlated with $\beta_{A}$, but is negatively correlated with $\alpha_{A}$ and $\beta_{B}$.

L.4) Firm B's IT investment is positively correlated with $\alpha_{A}$, but is negatively correlated with $\alpha_{B}$ and $\beta_{A}$.

Result L.1 is derived from (6). It simply states that the expected return of firm A's cost-reducing R\&D decreases as the market becomes more competitive with higher probability of success in firm B's cost-reducing R\&D. In addition, when the probability of knowhow leakage to firm B increases (large $\beta_{B}$ or small $\beta_{A}$ ), firm A's expected gains from cost-reducing R\&D will decrease, and thus we should observe a negative correlation between $k_{\alpha}^{A}$ and $\beta_{B}$, and a positive correlation between $k_{\alpha}^{A}$ and $\beta_{A}$. The economic explanation for L.2, which is derived from (8) is as follows. $k_{\beta}^{A}$ and $\alpha_{A}$ are positively correlated because firm A's gains from IT protection are higher either when firm A's knowhow is more valuable (large $\alpha_{A}$ ) or the risk of knowledge leakage is high (large $\beta_{B}$ ). However, other things being equal, if $\alpha_{B}$ increases, firm A's IT innovation is not helpful to maintain the cost advantage. Firm A's expected return decreases as $\alpha_{B}$ goes up. Firm A responds to a reduction in expected profit by cutting IT investment. Firm B's behaviors, which are described in L.3 (derived from (7)) and L.4 (derived from (9)) indicate substitution between IT innovation and cost-reducing R\&D. If the rival is more likely to have progress in process innovation, IT innovation is a more efficient way for firm B to catch up with the rival (Note 4). However, if the rival's IT protection becomes stronger (higher $\beta_{A}$ ), then devoting resources to cost-reducing $\mathrm{R} \& \mathrm{D}$ has relatively higher return.

\section{Welfare Analysis}

In this section, we would like to answer three questions: 1) How does economic espionage affect consumer surplus? 2) For the sake of information security, the government may provide subsidy to firms to encourage IT innovation. What is the welfare consequence of IT subsidy? 3) If the technology employed by firm B is illegally obtained by espionage, how would sales ban policy placed on firm B affect consumer's welfare?

\subsection{Espionage and Welfare}

IF there is espionage, the consumer surplus in a particular country is calculated by

$$
C S_{E}=\sum \tilde{\delta}_{r s} C S_{r s}
$$

where $C S_{r s}=\left(2 R-c_{r}-c_{s}\right)^{2} / 18, \quad r=L, M$ and $s=L, M, H$.

Proposition 2. The impact of economic espionage on consumer's welfare is ambiguous.

Proof

Let $C S_{\phi}=\sum \delta_{x y} C S_{x y}$, where $x=L, M$ and $y=M, H$, be the consumer surplus when there is no espionage. Here,

$C S_{x y}=\left(2 R-c_{x}-c_{y}\right)^{2} / 18$. Define $\Delta \tilde{\delta}_{x y} \equiv \tilde{\delta}_{x y}-\delta_{x y}$.

$$
C S_{E}-C S_{\phi}=\underset{+}{\tilde{\delta}_{L L}} C S_{L L}+\underset{-}{\Delta \tilde{\delta}_{L M}} C S_{L M}+\underset{+-}{\Delta \tilde{\delta}_{M M}} C S_{M M}+\underset{+-}{\Delta \tilde{\delta}_{L H}} C S_{L H}+\underset{+-}{\Delta \tilde{\delta}_{M H}} C S_{M H}
$$

The sign of (11) is uncertain and Proposition 2 follows.

Proposition 2 is in contrast to Whitney and Gaisford (1996). The reason is that they do not consider the impact of espionage on firm's cost-reducing R\&D. To see this, we can calculate

$$
\partial C S_{E} /\left.\partial \beta_{B}\right|_{\substack{\alpha_{A}=\alpha_{B}=0 \\ \beta_{A}=\beta_{B}=0}}=\frac{\left(c_{H}-c_{M}\right)\left(4 R-c_{H}-3 c_{M}\right)}{18}>0
$$

(12) indicates the result of Whitney and Gaisford (1996). i.e. espionage is beneficial to consumer surplus provided that firms do not engage in cost-reducing R\&D. However, as argued in Proposition 2 of the present paper, if we take cost-reducing $\mathrm{R} \& \mathrm{D}$ into consideration, it turns out that espionage might be harmful to consumer surplus. The intuition behind Proposition 2 is as follows. As argued by Whitney and Gaisford (1996), given technology level, consumers benefit from espionage because it is an efficient way to serve as a vehicle for technology diffusion. However, if technology level is no longer exogenously given, the free-rider problem induced by espionage impedes the incentive for cost-reducing $R \& D$, resulting in a negative effect for consumer 
welfare. It is shown in Proposition 2 that if the negative effect of espionage dominates the positive effect, the consumers are worse off. It is also found that, other things equal, a negative sign in (11) is more likely to occur if $\beta_{A}{ }^{\prime}\left(k_{\beta}^{A}\right)$ is large, which refers to the case where firm A's probability to succeed in IT R\&D is more sensitive to devoted capital. If $\beta_{A}{ }^{\prime}\left(k_{\beta}^{A}\right)$ is large, then with espionage, firm A will devote more capital to IT protection and less capital to cost-reducing $\mathrm{R} \& \mathrm{D}$, leading to fewer technology transfers and a smaller $C S_{E}$. In such a circumstance, espionage's positive effect for consumer welfare significantly shrinks and thus espionage can be harmful to consumers.

\subsection{IT Subsidy and Welfare}

Suppose that country A (B) subsidizes firm A's (B's) IT innovation by covering $s_{A}\left(s_{B}\right)$ fraction of IT innovation cost. The model becomes tedious after IT-subsidy is considered, and thus we will employ numerical simulation to analyze the impact of IT-subsidy on welfare. Let $\Delta t=t_{1}-t_{0}$. The probability to succeed in the interval of $\Delta t$ is assumed to follow Poisson distribution:

$$
\alpha_{A}=1-e^{-\lambda_{\alpha}^{A}}, \alpha_{B}=1-e^{-\lambda_{B}^{A}}, \beta_{A}=1-e^{-\lambda_{\beta}^{A}}, \beta_{B}=1-e^{-\lambda_{B}^{B}}
$$

where $\lambda_{\alpha}^{i}$ and $\lambda_{\beta}^{i}$ denote the average times of success in cost-reducing innovation and IT innovation for firm $i$ $(i=\mathrm{A}, \mathrm{B})$ in the interval of $\Delta t$. (Note 5) In addition, $\lambda_{\alpha}^{i}$ and $\lambda_{\beta}^{i}$ are increasing and concave in $k_{\alpha}^{i}$ and $k_{\beta}^{i}$ respectively and are assumed to be:

$$
\begin{aligned}
& \lambda_{\alpha}^{i}=\ln \left(e+k_{\alpha}^{i}\right)-1 \\
& \lambda_{\beta}^{i}=\ln \left(e+k_{\beta}^{i}\right)-1
\end{aligned}
$$

The following values are employed in the simulation: $c_{L}=0, c_{M}=5$ and $c_{H}=10$. Figure 1 and Figure 2 show the impact of IT subsidy on consumer surplus when $R=100$. It is found that ceteris paribus, subsidy on the firm whose unit cost is high (low) at $\mathrm{t}=\mathrm{t}_{0}$ is beneficial (detrimental) to consumer surplus. The reason is that subsidy on firm B's IT innvation rasises technology transfer, while the subsidy on firm A's IT investment decreases it.

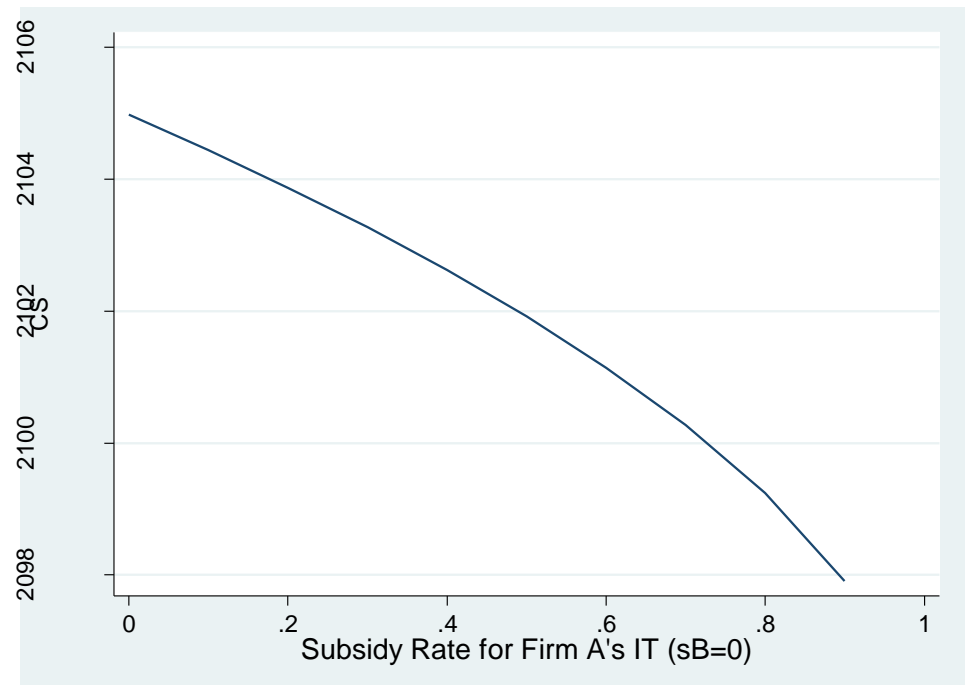

Figure 1. How consumer surplus responds to firm A's IT subsidy 


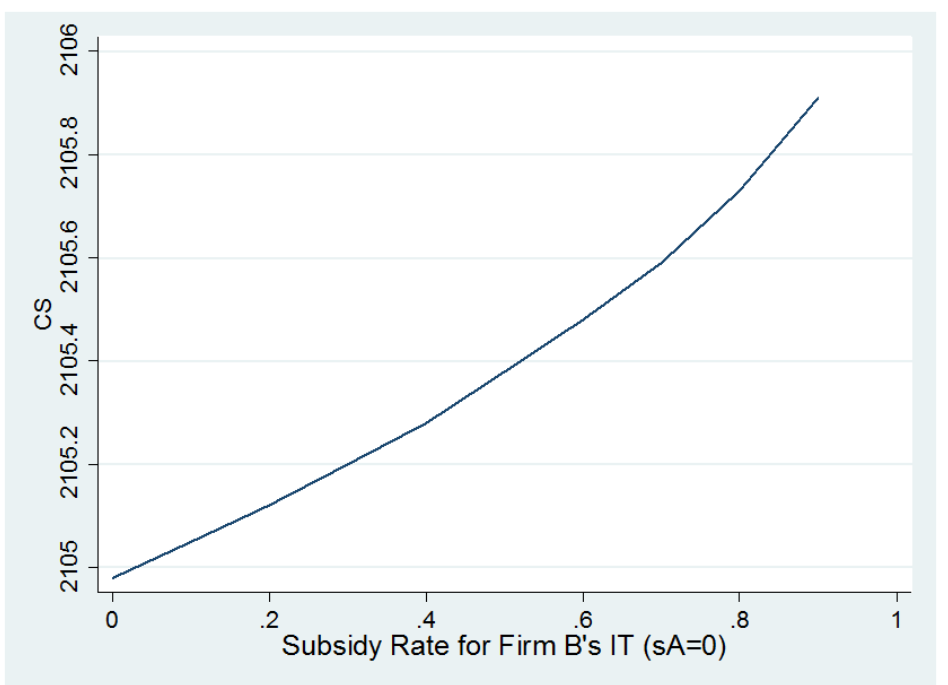

Figure 2. How consumer surplus responds to firm B's IT subsidy

\subsection{Sales Ban Policy and Welfare}

Suppose that sales of goods produced by illegally obtained technology are prohibited in country A. I will discuss the welfare consequence of this sales ban policy in this section. Table 2 summarizes the profit of firm A and firm $\mathrm{B}$ in corresponding innovation outcomes under the regulation of sales ban policy.

Table 2. Payoff matrix in market A with sales ban policy

\begin{tabular}{|c|c|c|c|c|c|}
\hline & Firm B & both succeed & $\begin{array}{l}\text { only cost-reducing } \\
\text { R\&D succeeds }\end{array}$ & $\begin{array}{l}\text { only IT innovation } \\
\text { succeeds }\end{array}$ & both fail \\
\hline Firm A & Probability & $\alpha_{B} \beta_{B}$ & $\alpha_{B}\left(1-\beta_{B}\right)$ & $\left(1-\alpha_{B}\right) \beta_{B}$ & $\left(1-\alpha_{B}\right)\left(1-\beta_{B}\right)$ \\
\hline both succeed & $\alpha_{A} \beta_{A}$ & $\pi_{L M}^{A}, \pi_{L M}^{B}$ & $\pi_{L M}^{A}, \pi_{L M}^{B}$ & $\pi_{L H}^{A}, \pi_{L H}^{B}$ & $\pi_{L H}^{A}, \pi_{L H}^{B}$ \\
\hline $\begin{array}{l}\text { only } \\
\text { cost-reducing } \\
\text { R\&D succeeds }\end{array}$ & $\alpha_{A}\left(1-\beta_{A}\right)$ & $\pi_{L}^{A}, 0$ & $\pi_{L M}^{A}, \pi_{L M}^{B}$ & $\pi_{L}^{A}, 0$ & $\pi_{L H}^{A}, \pi_{L H}^{B}$ \\
\hline $\begin{array}{l}\text { only IT } \\
\text { innovation } \\
\text { succeeds }\end{array}$ & $\left(1-\alpha_{A}\right) \beta_{A}$ & $\pi_{M M}^{A}, \pi_{M M}^{B}$ & $\pi_{M M}^{A}, \pi_{M M}^{B}$ & $\pi_{M H}^{A}, \pi_{M H}^{B}$ & $\pi_{M H}^{A}, \pi_{M H}^{B}$ \\
\hline both fail & $\left(1-\alpha_{A}\right)\left(1-\beta_{A}\right)$ & $\pi_{M M}^{A}, \pi_{M M}^{B}$ & $\pi_{M M}^{A}, \pi_{M M}^{B}$ & $\pi_{M}^{A}, 0$ & $\pi_{M H}^{A}, \pi_{M H}^{B}$ \\
\hline
\end{tabular}

Note. $\pi_{L}^{A}\left(\pi_{M}^{A}\right)$ denotes firm A's monopolistic profit in market A with unit cost $c_{L}\left(c_{M}\right) . \quad \pi_{x y}^{i}$ is firm $i$ 's profit in one market when firm A has unit cost $c_{x}$ and firm B has unit cost $c_{y}$, where $i=A, B ; x=L, M$ and $y=M, H$.

Firm A's expected profit becomes

$$
\begin{aligned}
\hat{\Pi}_{A}= & {\left[\hat{\delta}_{M H} \pi_{A}\left(c_{M}, c_{H}\right)+\hat{\delta}_{L H} \pi_{A}\left(c_{L}, c_{H}\right)+\hat{\delta}_{L M} \pi_{A}\left(c_{L}, c_{M}\right)+\hat{\delta}_{M M} \pi_{A}\left(c_{M}, c_{M}\right)+\hat{\delta}_{L} \pi_{A}\left(c_{L}\right)+\hat{\delta}_{M} \pi_{A}\left(c_{M}\right)\right]+} \\
& {\left[\tilde{\delta}_{M H} \pi_{A}\left(c_{M}, c_{H}\right)+\tilde{\delta}_{L H} \pi_{A}\left(c_{L}, c_{H}\right)+\tilde{\delta}_{L M} \pi_{A}\left(c_{L}, c_{M}\right)+\tilde{\delta}_{M M} \pi_{A}\left(c_{M}, c_{M}\right)+\tilde{\delta}_{L L} \pi_{A}\left(c_{L}, c_{L}\right)\right]-k_{\alpha}^{A}-k_{\beta}^{A} }
\end{aligned}
$$

Here, $\pi_{A}\left(c_{L}\right)=\left(R-c_{L}\right)^{2} / 4$ and $\pi_{A}\left(c_{M}\right)=\left(R-c_{M}\right)^{2} / 4$ respectively denote the monopolistic profit of firm A with unit cost $c_{L}$ and $c_{M}$ when sales ban is executed on firm B's products. The terms in the first (second) bracket of (15) stand for the profit from country A (B). Similarly, firm B's expected profit is given by

$$
\begin{aligned}
\hat{\Pi}_{B}= & {\left[\hat{\delta}_{M H} \pi_{B}\left(c_{M}, c_{H}\right)+\hat{\delta}_{L H} \pi_{B}\left(c_{L}, c_{H}\right)+\hat{\delta}_{L M} \pi_{B}\left(c_{L}, c_{M}\right)+\hat{\delta}_{M M} \pi_{B}\left(c_{M}, c_{M}\right)\right]+\left[\tilde{\delta}_{M H} \pi_{B}\left(c_{M}, c_{H}\right)+\tilde{\delta}_{L H} \pi_{B}\left(c_{L}, c_{H}\right)\right.} \\
& \left.+\tilde{\delta}_{L M} \pi_{B}\left(c_{L}, c_{M}\right)+\tilde{\delta}_{M M} \pi_{B}\left(c_{M}, c_{M}\right)+\tilde{\delta}_{L L} \pi_{B}\left(c_{L}, c_{L}\right)\right]-k_{\alpha}^{B}-k_{\beta}^{B}
\end{aligned}
$$


The following values are employed for simulation: $\left(c_{L}, c_{M}, c_{H}\right)=(0,5,10)$ and $\mathrm{R}>20$. The simulation results reveal that the impact of sales ban policy depends on the market size. Figure 3 shows the changes in R\&D investment due to sales ban at different market size.

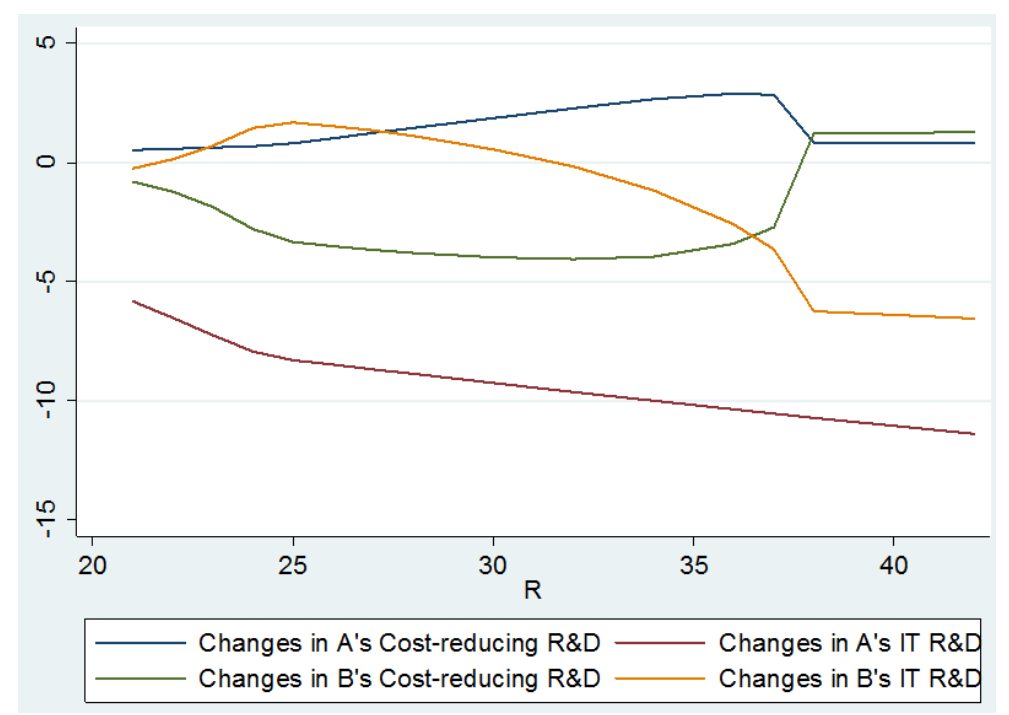

Figure 3. Changes in R\&D investment due to sales ban at different level of market size

It is found that sales ban policy does not necessarily discourage espionage activities. When market size is small, sales ban policy alternatively increases espionage. Only when market size is sufficiently large, espionage activities are reduced due to sales ban. The reason is as follows. Sales ban policy reduces firm A's investment in IT innovation because if the technology is stolen by the rival, firm A can push for a sales ban on rival's product and firm A can earn monopolistic profit in market A. Given a reduction in firm A's IT investment, firm B considers two effects. The first effect is the expected loss in profit due to sales ban in market A. The second effect is the benefit from espionage in market B, where sales ban does not apply. When the market size is small, the latter effect dominates the first effect. As a consequence, firm B responds to the reduction in firm A's IT investment by raising espionage activities. However, when the market size is large, the loss in market A becomes so significant and thus the first effect will instead dominate the latter one.

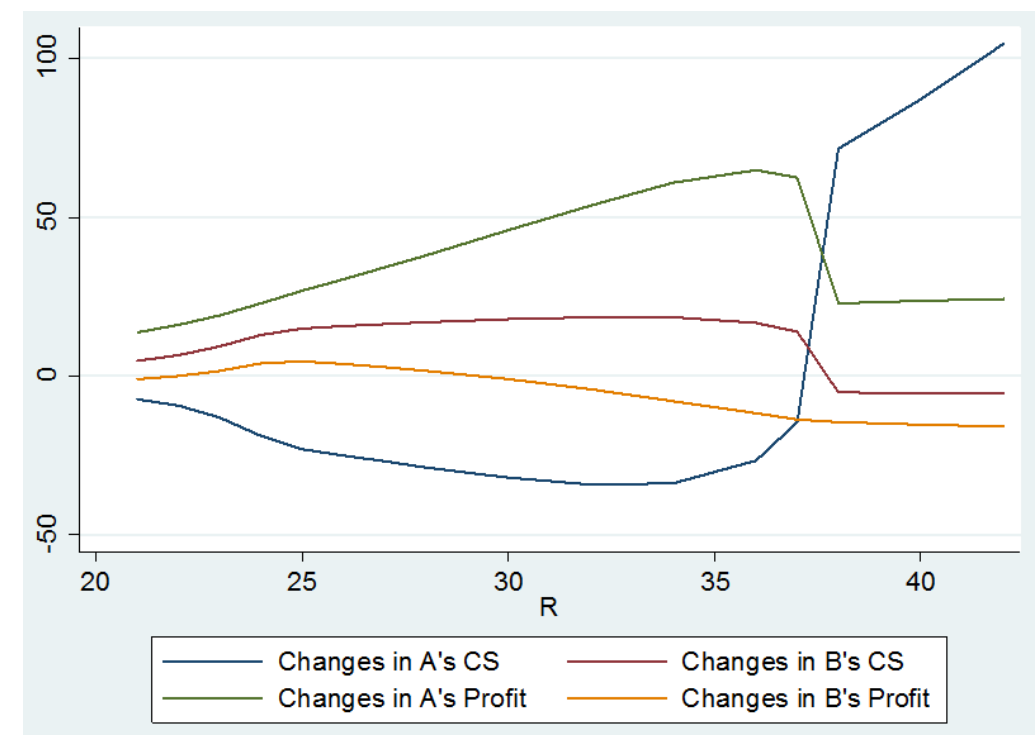

Figure 4. Changes in welfare due to sales ban at different market size 
The welfare consequence of sales ban policy is depicted in Figure 4. Sales ban policy in market A is beneficial to firm A but the impact on consumer surplus differs in market size. If the market size is small such that sales ban policy can not deter espionage, then sales ban policy is detrimental to consumer surplus (Note 6). However, I also find that sales ban policy can be welfare-improving: if market size is sufficiently large such that firm B ceases espionage due to sales ban policy, then consumer surplus increases when sales ban applies.

It should be noted that the parameter values imply that (11) is positive, indicating consumers are better off with espionage activities. Yet, we also find that if market size is large such that espionage activities are deterred by sales ban policy, then CS increases. At first glance, these two welfare consequences seem to contradict to each other, but actually they do not. The reason why sales ban can improve CS is as follows. Sales ban policy not only protects firm A's expected return on cost-reducing R\&D but also provides extra benefits to firm A by offering monopolistic market power. Therefore, firm A will respond to sales ban by increasing cost-reducing $R \& D$ and reducing investment in IT innovation. Higher $k_{\alpha}^{A}$ and lower $k_{\beta}^{A}$ are both beneficial to consumers, but monopolistic market power hurts consumers. When market size is small such that espionage is not deterred, the latter effect is stronger than the former one, leading to worse CS in market A. However, as market size is sufficiently large such that espionage activities cease, firm A's monopolistic position is no longer maintainable because sales ban will not execute in this case. Consequently, the positive effect on CS due to more cost-reducing R\&D and less capital devoted to IT innovation by firm A will dominate.

\section{Concluding Remarks}

This paper develops a simple duopoly model to analyze the impact of economic espionage on investment incentives in both cost-reducing and IT innovation. I find that economic espionage will reduce both firms' investment in cost-reducing $\mathrm{R} \& \mathrm{D}$ due to free-rider problem. Therefore, economic espionage has mixed effects on consumer's welfare. When technology-transfer effect dominates free-rider effect, then economic espionage is welfare improving. However, when the latter dominates instead, then espionage is harmful to consumers.

This paper provides welfare consequence for IT subsidy and sales ban policy by simulation. It is found that subsidy on B's IT innovation increases firm B's as well as consumers' welfare. Yet, IT subsidy to firm A is beneficial only to firm A, but is detrimental to consumers. The simulation result for sales ban policy shows that to deter economic espionage by sales ban, the market size should be sufficiently large. If the market size is small, sales ban may alternatively encourage espionage activities. The welfare analysis of sales ban policy shows that if market A is small, sales ban increases firm A's profit at the expense of reducing consumer surplus in market A. However, when market A is large such that espionage is deterred, then both consumers in market A and firm A can benefit from sales ban. One reason that sales ban policy cannot deter espionage is that I assume sales ban policy applies only in market A. If both countries have harmonious policy to protect intellectual property rights (IPRs), then applying sales ban in both countries can deter espionage. However, harmonious IPR policy across countries needs international negotiation and coordination.

\section{Acknowledgments}

This work was supported by the Ministry of Science and Technology in Taiwan [grant number 103-2410-H-032-014-].

\section{References}

Barrachina, A., Tauman, Y., \& Urbano, A. (2014). Entry and espionage with noisy signals. Games and Economic Behavior, 83(0), 127-146. http://dx.doi.org/10.1016/j.geb.2013.10.005

Billand, P., Bravard, C., Chakrabarti, S., \& Sarangi, S. (2010). Spying in Multi-Market Oligopolies. FEEM Working Paper, No.117.2010.

Ho, S. J. (2008). Extracting the information: Espionage with double crossing. Journal of Economics, 93(1), 31-58. http://dx.doi.org/10.1007/s00712-007-0290-2

Matsui, A. (1989). Information leakage forces cooperation. Games and Economic Behavior, 1(1), 94-115. http://dx.doi.org/10.1016/0899-8256(89)90007-9

Provan, J. S. (2008). The Use of Spies in Strategic Situations: Preliminary Report: Technical Report UNC/STOR/07/01. 
Solan, E., \& Yariv, L. (2004). Games with espionage. Games and Economic Behavior, 47(1), 172-199. http://dx.doi.org/10.1016/S0899-8256(03)00177-5

Whitney, M. E., \& Gaisford, J. D. (1996). Economic Espionage as Strategic Trade Policy. The Canadian Journal of Economics / Revue canadienne d'Economique, 29, S627-S632. http://dx.doi.org/10.2307/136121

Whitney, M. E., \& Gaisford, J. D. (1999). An Inquiry Into the Rationale for Economic Espionage. International Economic Journal, 13(2), 103-123. http://dx.doi.org/10.1080/10168739900000040

\section{Notes}

Note 1. I do not consider espionage between firms in the same country because the focus of this paper is placed on cross-country espionage.

Note 2. Throughout the paper, I assume there is no discounting.

Note 3. Since $\Delta \pi_{A}\left(c_{H}\right)-\Delta \pi_{A}\left(c_{H}\right)<0$, and $\pi_{A}\left(c_{L}, c_{L}\right)-\pi_{\Lambda}\left(c_{L}, c_{H}\right)<0$, we have $\Omega<0$.

Note 4. For firm B, success in cost-reducing R\&D can only lead to unit production cost $C_{M}$; however, success in spionage may lead to $C_{L}$.

Note 5. Let $x(x=0,1,2, \ldots)$ be the number of event that innovation succeeds. The probability of a firm to have successful innovation is $1-\operatorname{prob}(x=0)=1-\frac{e^{-\lambda} \lambda^{0}}{0 !}=1-e^{-\lambda}$, where $\lambda$ is the parameter of Poisson distribution.

Note 6. According to the simulation, when market size $\mathrm{R}$ is greater than 38 , firm B will stop investing in IT innovation.

\section{Copyrights}

Copyright for this article is retained by the author(s), with first publication rights granted to the journal.

This is an open-access article distributed under the terms and conditions of the Creative Commons Attribution license (http://creativecommons.org/licenses/by/3.0/). 